\title{
Science is so costly because of wars
}

\author{
Minh-Hoang Nguyen \\ Centre for Interdisciplinary Social Research \\ Phenikaa University
}

Yen Nghia, Ha Dong, Hanoi 100803, Vietnam

February 26, 2022
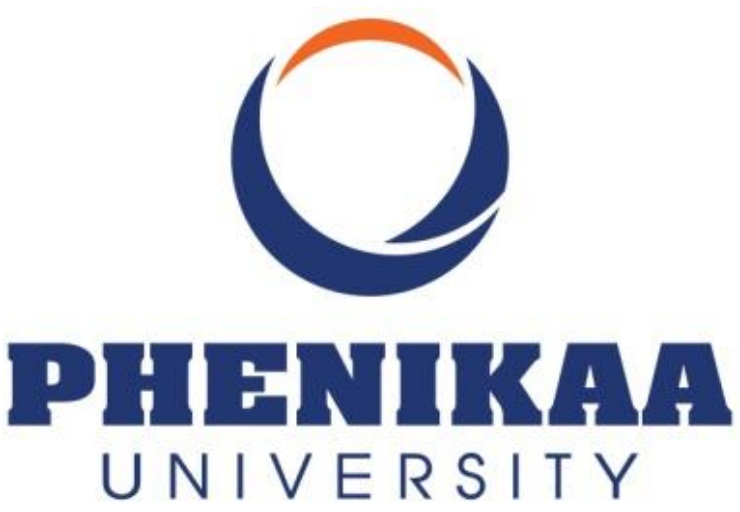

$* * * * * * * *$

Investment in science has led human civilization to many achievements in science and technology, including military weapons. Advanced weapons nowadays may seem cool and fancy than stick and stone in the stone age, or swords and arrows in the middle age, but they are also surely a thousand-time more powerful and deadlier.

At the first look, it might seem that our investment in science has been paid off, but it is not true in the scenarios that such weapons are used for waging war - the worst scenario of a conflict. War always leads to deaths and devastation. Cultural and environmental heritages cannot be rebuilt, and humans cannot be reborn $[1,2]$. They are, to some extent, invaluable.

Weapons do not destroy things and kill people by themselves, but they are used and controlled by the hands of humans. No matter how advanced they are, they are still tools that serve humans' interests. Therefore, it is unwise to expect the sole development of technology and science can help resolve conflicts. Conflicts need to be resolved through humane approaches aided by science and technology developments. Besides advances in science and technology, humanities and social sciences developments are indispensable for resolving conflicts and improving well-being [3]. 
The cost of science can be either rational or irrational, depending on its purposes [4]. So, don't make our science costly by making war. Otherwise, human civilizations will resolve conflicts using "sticks and stones", as Albert Einstein quoted.

\section{References}

1. Daley B, McCarthy D, Murphy A, Pollé A, Weda R. (n.d.). Heritage at Risk: The Devastation of War. EUROPEANA. Retrieved from:

https://www.europeana.eu/en/exhibitions/heritage-at-risk/the-devastation-ofwar

2. Ray M. (n.d.). 8 Deadliest Wars of the 21st Century. Retrieved from: https://www.britannica.com/list/8-deadliest-wars-of-the-21st-century

3. Vuong QH, Nguyen MH, Le TT. (2021). A mindsponge-based investigation into the psycho-religious mechanism behind suicide attacks. Warsaw, Poland: De Gruyter.

4. Vuong QH. (2018). The (ir)rational consideration of the cost of science in transition economies. Nature Human Behaviour, 2(1),5. 